Review

\title{
A New Exoplanet Reveals its Identity
}

\author{
${ }^{1}$ Nicolae Petrescu, ${ }^{2}$ Raffaella Aversa, ${ }^{2}$ Antonio Apicella and ${ }^{3}$ Florian Ion Tiberiu Petrescu

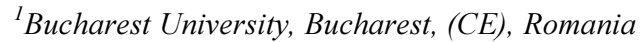 \\ ${ }^{2}$ Department of Architecture and Industrial Design, Advanced Material Lab, \\ Second University of Naples, 81031 Aversa (CE), Italy \\ ${ }^{3}$ ARoTMM-IFToMM, Bucharest Polytechnic University, Bucharest, (CE), Romania
}

\author{
Article history \\ Received: 30-05-2018 \\ Revised: 31-05-2018 \\ Accepted: 4-06-2018 \\ Corresponding Author: \\ Florian Ion Tiberiu Petrescu \\ ARoTMM-IFToMM, \\ Bucharest Polytechnic \\ University, Bucharest, (CE), \\ Romania \\ E-mail: scipub02@gmail.com
}

Abstract: Positioned approximately 70 light years from Earth a sun named by astronomer HD 97658, is nearly bright enough to be seen even with the naked eye. The more interesting part of the problem lies in the fact that this sun, this star, also has an exoplanet HD 97658b, the size of which is approximately double compared to our planet Earth and having a smaller mass compared to our planet about eight times. HD $97658 \mathrm{~b}$ is basically a super-Earth, a great planet in cosmic space, for which there is no example in our solar system. Even if its discovery was made long ago, its size and mass were recently determined by Diana Dragomir, a postdoctoral astronomer with the Las Cumbres Observatory Global Observatory (LCOGT) of UC Santa Barbara University. As part of his research, Dragomir carefully studied various transits of this exoplanet with the help of the cosmic telescope, able to determine Microvariability and Oscillations of Stars (MOST). That telescope was launched in 2003 in an orbit about 510 miles high. Dragomir has been able to analyze the data read by the telescope, using the code written by LCOGT postdoctoral colleague Jason Eastman. The results were recently published online in the Astrophysical Journal Letters. It is considered a super planet, a super-Earth, an exoplanet having the mass and dimensions in the area of our solar system (between Earth and Neptune). It does not imply, as other obligatory researchers assert, the temperatures, the composition, the total similarity to the environment on Earth. These additional requirements are beyond the definition of a super-Earth and may represent additional desires. Superpowder refers to the mass of the planet and does not involve a temperature, composition or a similar environment on Earth. The brightness of HD 97658 allows astronomers to study it closely, this star as well as its planet, in ways that are not possible for most exosystems (which have been discovered around the weaker stars). HD 97658b was discovered relatively recently in 2011 by a team of specialized astronomers using the Keck Observatory and a technique called Doppler. Initially, only a lower limit could be established for the mass of the planet and nothing was known about its size. Transits, such as those observed by Dragomir, can occur only when a planet's orbit is wearing it in front of the parent star, thus reducing the amount of light that we see from the star (so easy) when overlapping. The decrease in brightness occurs in each orbit if the orbit happens to be almost exactly aligned with our line of sight on Earth. For a planet that is not much larger than our Earth, around a star nearly as great as our Sun, the interruption in the light is very small and short but still detectable by the specialized telescope, MOST SPACE.

Keywords: NASA, Earth, Exosystems, Exoplanets, Solar Systems, A SuperEarth, Sun, Stars, Doppler, Great Planet, Cosmic Space, Exoplanet Size and Mass, Microvariability and Oscillations of Stars, Astronomers, Cosmic Telescope 


\section{Introduction}

An extrasolar planet is a planet that is orbiting a star other than the Sun, belonging to a planetary system other than our Solar System, or it is moving freely through the galaxy.

In our Galaxy, there are billions of stars and it is estimated that over $15 \%$ of them have plants that surround them. There is also the planet that orbits around gray dwarf stars or plants that move freely through the galaxy.

The discovery of exoplanets is difficult because they are remote and lacking their own light. In June 2011, over 500 extrasolar planets have already been discovered. The mass of these planets is of the mass of the planet Jupiter. The vast majority of them have been detected through observations on radial speed and other indirect methods rather than using real images. To date, more than 2000 exoplanets have been discovered (2099 exoplanets in 1342 solar systems, of which 510 planetary systems with more than one planet on 1 April 2016).

Another method used to discover exoplanets is the technique of microgravity lenses, which is based on the deflection of light from a star when it is behind the gravity of the field of another star.

Several extragalactic exoplanets have been discovered.

Exoplanets are also important for the eventual existence of alien life because stars cannot shelter life, being too hot for it.

\section{Methods and Materials}

Positioned approximately 70 light years from Earth a sun named by astronomer HD 97658, is nearly bright enough to be seen even with the naked eye. The more interesting part of the problem lies in the fact that this sun, this star, also has an exoplanet HD 97658b, the size of which is approximately double compared to our planet Earth and having a smaller mass compared to our planet about eight times. HD $97658 \mathrm{~b}$ is basically a super-Earth, a great planet in cosmic space, for which there is no example in our solar system.

Even if its discovery was made long ago, its size and mass were recently determined by Diana Dragomir, a postdoctoral astronomer with the Las Cumbres Observatory Global Observatory (LCOGT) of UC Santa Barbara University. As part of his research, Dragomir carefully studied various transits of this exoplanet with the help of the cosmic telescope, able to determine Microvariability and Oscillations of Stars (MOST). That telescope was launched in 2003 in an orbit about 510 miles high. Dragomir has been able to analyze the data read by the telescope, using the code written by LCOGT postdoctoral colleague Jason Eastman. The results were recently published online in the Astrophysical Journal Letters.

It is considered a super planet, a super-Earth, an exoplanet having the mass and dimensions in the area of our solar system (between Earth and Neptune). It does not imply, as other obligatory researchers assert, the temperatures, the composition, the total similarity to the environment on Earth. These additional requirements are beyond the definition of a super-Earth and may represent additional desires. Superpowder refers to the mass of the planet and does not involve a temperature, composition or a similar environment on Earth.

The brightness of HD 97658 allows astronomers to study it closely, this star as well as its planet, in ways that are not possible for most exosystems (which have been discovered around the weaker stars).

HD 97658b was discovered relatively recently in 2011 by a team of specialized astronomers using the Keck Observatory and a technique called Doppler. Initially, only a lower limit could be established for the mass of the planet and nothing was known about its size.

Transits, such as those observed by Dragomir, can occur only when a planet's orbit is wearing it in front of the parent star, thus reducing the amount of light that we see from the star (so easy) when overlapping. The decrease in brightness occurs in each orbit if the orbit happens to be almost exactly aligned with our line of sight on Earth. For a planet that is not much larger than our Earth, around a star nearly as great as our Sun, the interruption in the light is very small and short but still detectable by the specialized telescope, MOST SPACE.

The first report on transit in the HD 97658 system in 2011 was just a false alarm, so the whole story of the new discovery risks to die from the beast and remain buried definitively. Dragomir knew that the ephemeris of the planet's orbit (a timing to predict when the planet could pass the star) was not accurate and had the power of persuasion for the MOST team not to stop research but to expand search parameters and then the last possible window of observation of this star last year when it all seemed just lost time and the abandonment of the study was already floating in the air, so the long awaited event occurred on its own, the data then showing tantalizing signs of a transit - monster, but unsafe though. So, resuming the abandonment study and only one year later, MOST revised HD 97658 and found clear evidence of the planet's transit, allowing Dragomir and the MOST team to evaluate them for the first time, including the size and mass of the planet.

After measuring the size and mass of the exoplanet, it was then possible to determine by its calculation its density, which in turn allows astronomers to continue to say something about its composition. The measurement of the properties of the super-earth, in particular, tells us whether they are mainly rocky giants, rich in water, mini-gas or something completely different. These are particularly complex problems that can be anticipated as soon as you know the first data about the mass, volume, density of a discovered exoplanet. 
The average density of HD $97658 \mathrm{~b}$ is about four grams per cubic centimeter, about a third of the lead density, but denser than most known rocks. Astronomers see great value in this value - about $70 \%$ of Earth's average density - because the surface gravity of HD 97658 b could maintain a thick atmosphere. Although it is unlikely that alien life can breathe those gases, yet the planet allows them to exist and their possible later modification to obtain a friendly atmosphere. The planet orbits its sun every 9.5 days, at a distance ten times closer than we are from our Sun. If a planet is too close to its star, it is too hot; if it's too far away, it's too cold, but if it's in the area, it's "just right" for the ocean of liquid water, a prerequisite for the life here on Earth.

In recent years, systems with massive orbital planets have proved to be quite common, despite being generally unexpected. The current number of confirmed exoplanets exceeds 600 , most of which are detected by radiological surveys, which are generally biased toward the detection of massive planets (about the mass of Jupiter) in small orbits. HD $97658 \mathrm{~b}$ orbits its star at a greater distance (distant) than many of the exoplanets currently known. HD 97658 b is just the second super-Earth known to have a very bright star (Fig. 1).

This discovery is added to the small sample of the over-earth around the brilliant stars, "Dragomir said. In addition, it has even a longer period of time than the many exoplanets known for transit around the brilliant stars, including the only super-Earth in this category. The longer period means that it is colder than many exoplanets closer to their stars. The properties of $97658 \mathrm{~b}$ are part of the progress towards understanding the exoplanets in the habitable area (Science Daily, 2013).

Figure 2 shows an artistic representation of the HD 189733 b planet that is at 63 light years in the Vulpecula constellation. It was discovered in 2005. Most of the exoplanets found momentarily are within a 300-year radius of light around the Sun (Fig. 3). In the Fig. 4 one can see the planet Fomalhaut b, represented in the box against the background of the interstellar dust cloud. Imagine created by the cosmic space telescope (NASA photo). Figure 5 shows the image of the GJ 758 system, taken with Subaru Telescope HiCIAO in the near infrared. Figure 6 shows the Coronagraph image of AB Pictoris showing its tiny companion (bottom left). The data was obtained on 16 March 2003 with NACO on the VLT, using a 1.4 arcsec occulting mask on top of AB Pictoris. In Fig. 7 one can see Our solar system compared to 55 Cancri system (Webster et al., 2018; Aversa et al., 2017a; 2017b; 2017c; 2017d; 2017e; 2017f; 2016a; 2016b; 2016c; 2016d; 2016e; 2016f; 2016g; 2016h; 2016i; 2016j; 2016k; 2016l; 2016m; 2016n; 2016o; Mirsayar et al., 2017; Petrescu and Petrescu, 2016a; 2016b; 2016c; 2013a; 2013b; 2013c; 2013d; 2012a; 2012b; 2012c; 2012d; 2011a; 2011b; Petrescu, 2016; 2012a; 2012b; 2009; Petrescu and Calautit, 2016a; 2016b; Petrescu et al., 2016a; 2016b; 2016c; Petrescu et al., 2017a; 2017b; 2017c; 2017d; $2017 \mathrm{e} ; 2017 \mathrm{f} ; 2017 \mathrm{~g} ; 2017 \mathrm{~h} ; 2017 \mathrm{i} ; 2017 \mathrm{j} ; 2017 \mathrm{k}$; 20171; 2018 a-n; Zubritsky, 2017).

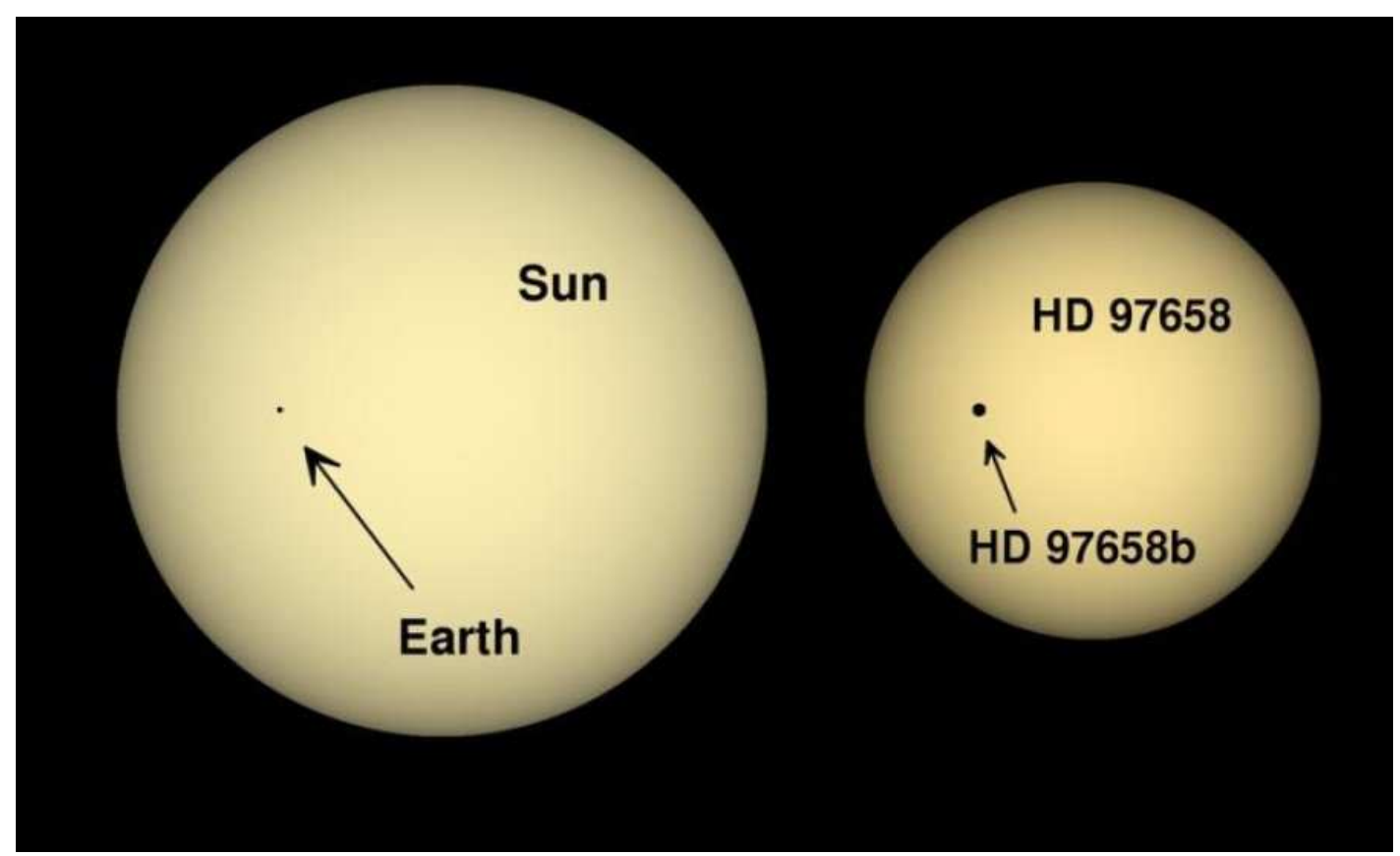

Fig. 1: The relative size of the Earth and Sun next to those of HD 97658 (the star) and HD 97658b (the super-Earth exoplanet). Credit: Jason Eastman and Diana Dragomir 


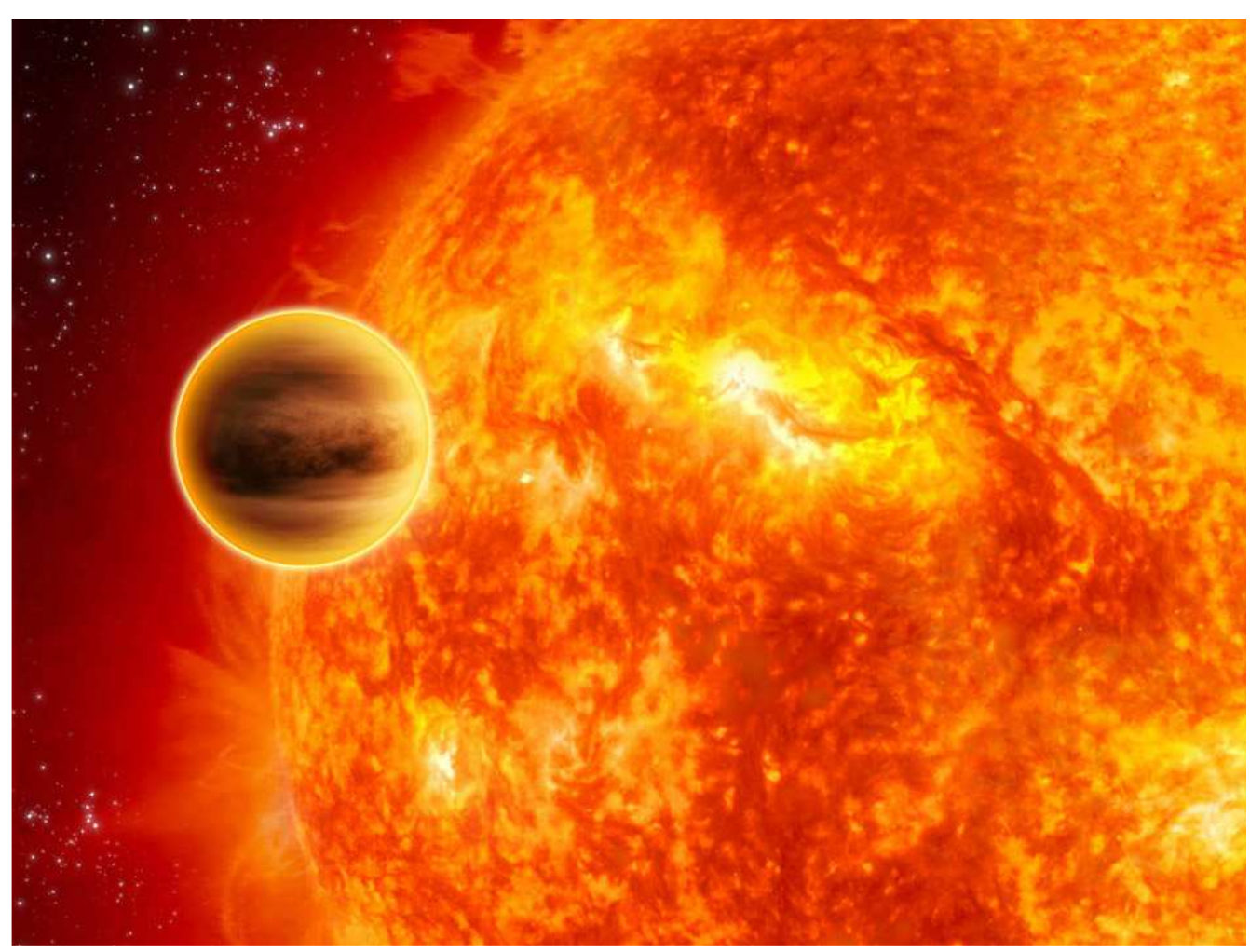

Fig. 2: Artistic representation of the HD 189733b planet that is at 63 light years in the Vulpecula constellation. It was discovered in 2005.

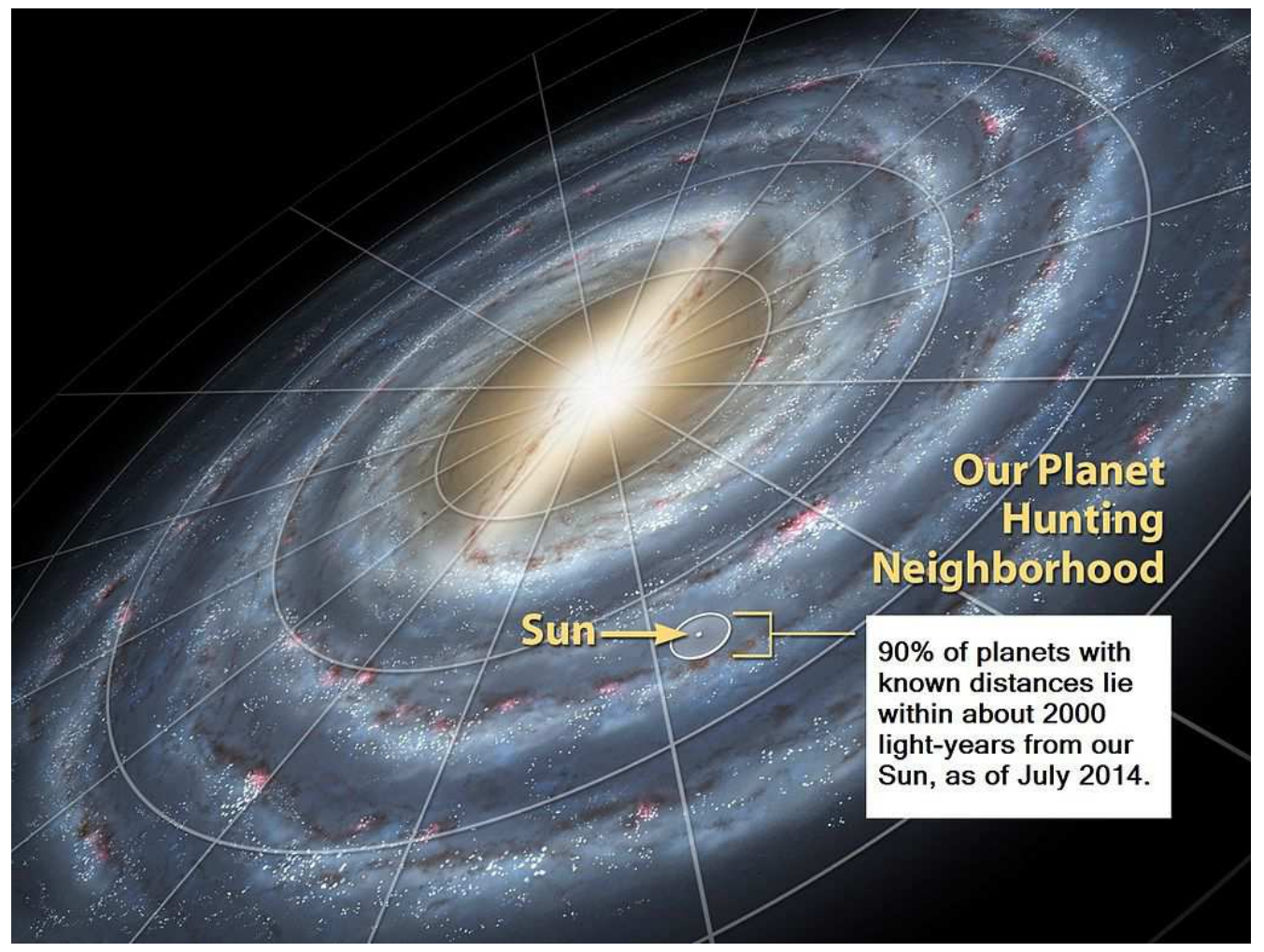

Fig. 3: Most of the exoplanets found momentarily are within a 300-year radius of light around the Sun 


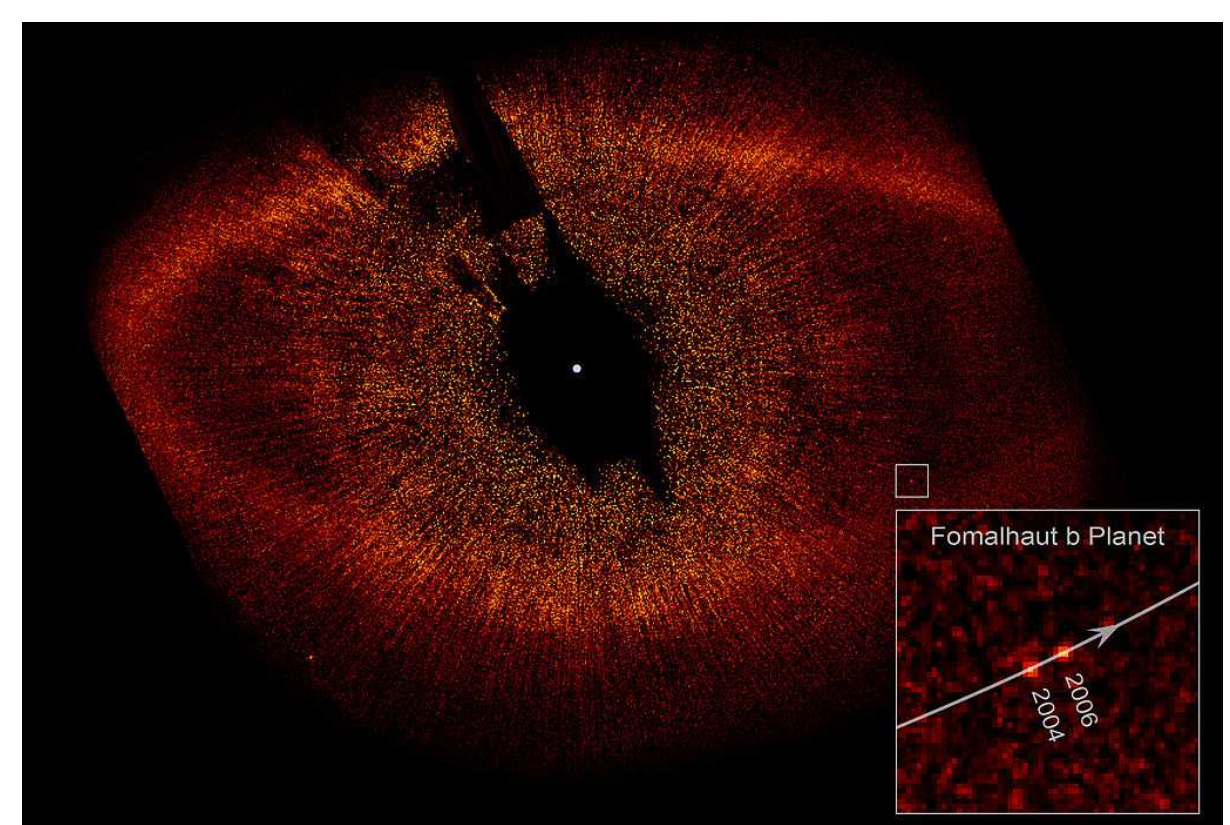

Fig. 4: Planet Fomalhaut b, represented in the box against the background of the interstellar dust cloud. Imagine created by the cosmic space telescope (NASA photo)

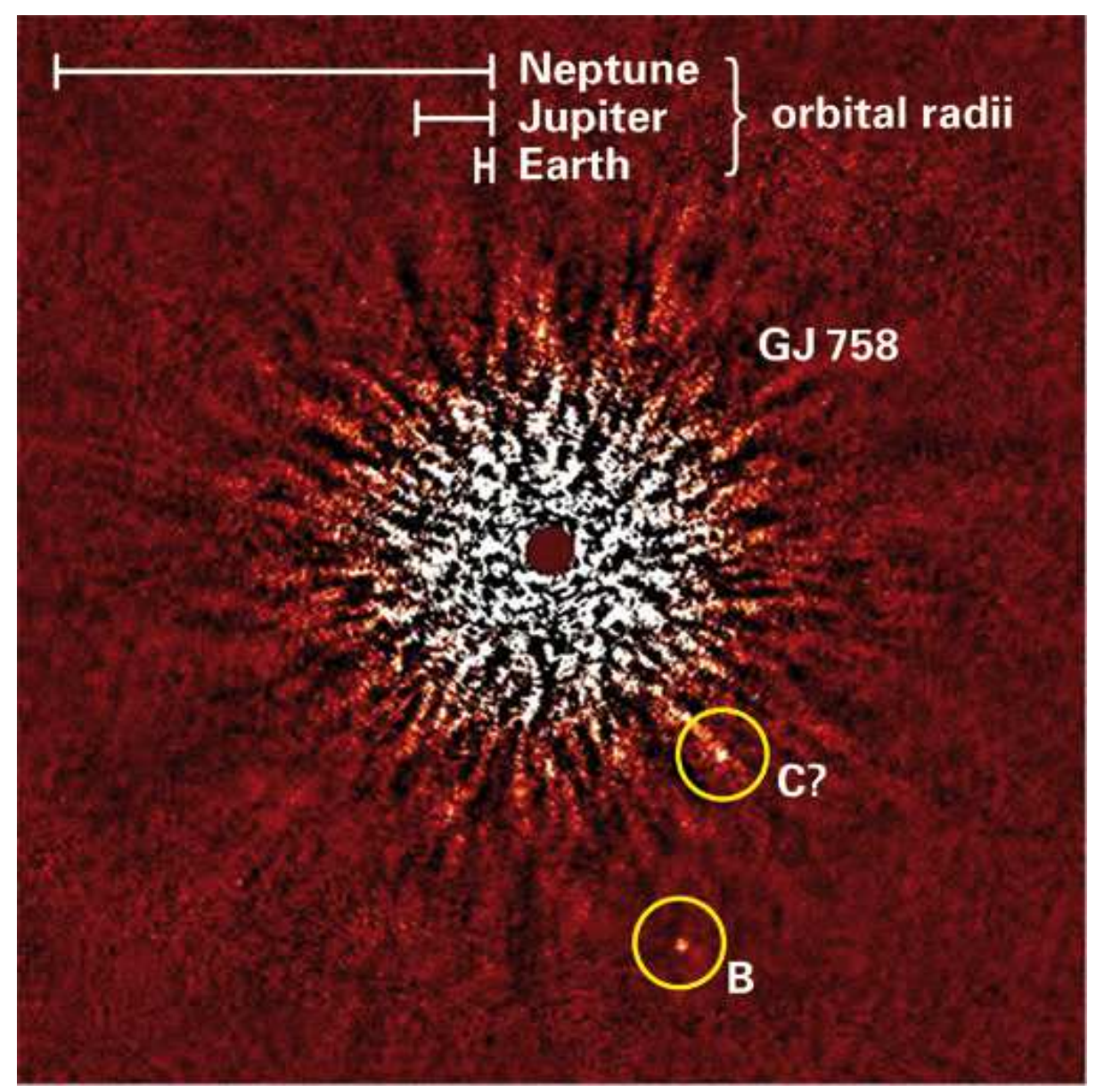

Fig. 5: Discovery image of the GJ 758 system, taken with Subaru Telescope HiCIAO in the near infrared. 


\section{AB Pic}

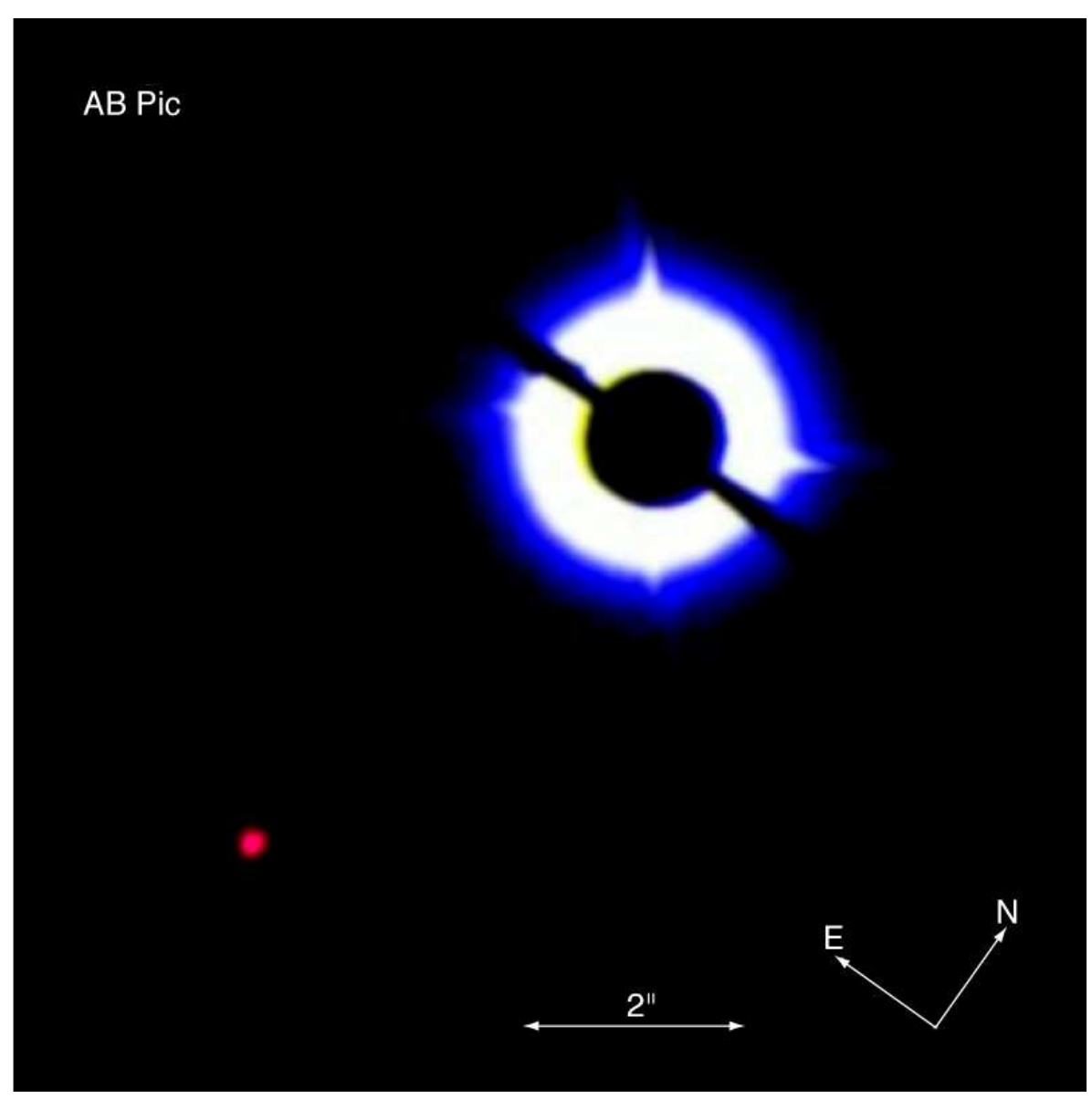

Fig. 6: Coronagraph image of $\mathrm{AB}$ Pictoris showing its tiny companion (bottom left). The data was obtained on $16 \mathrm{March} 2003$ with NACO on the VLT, using a 1.4 arcsec occulting mask on top of AB Pictoris

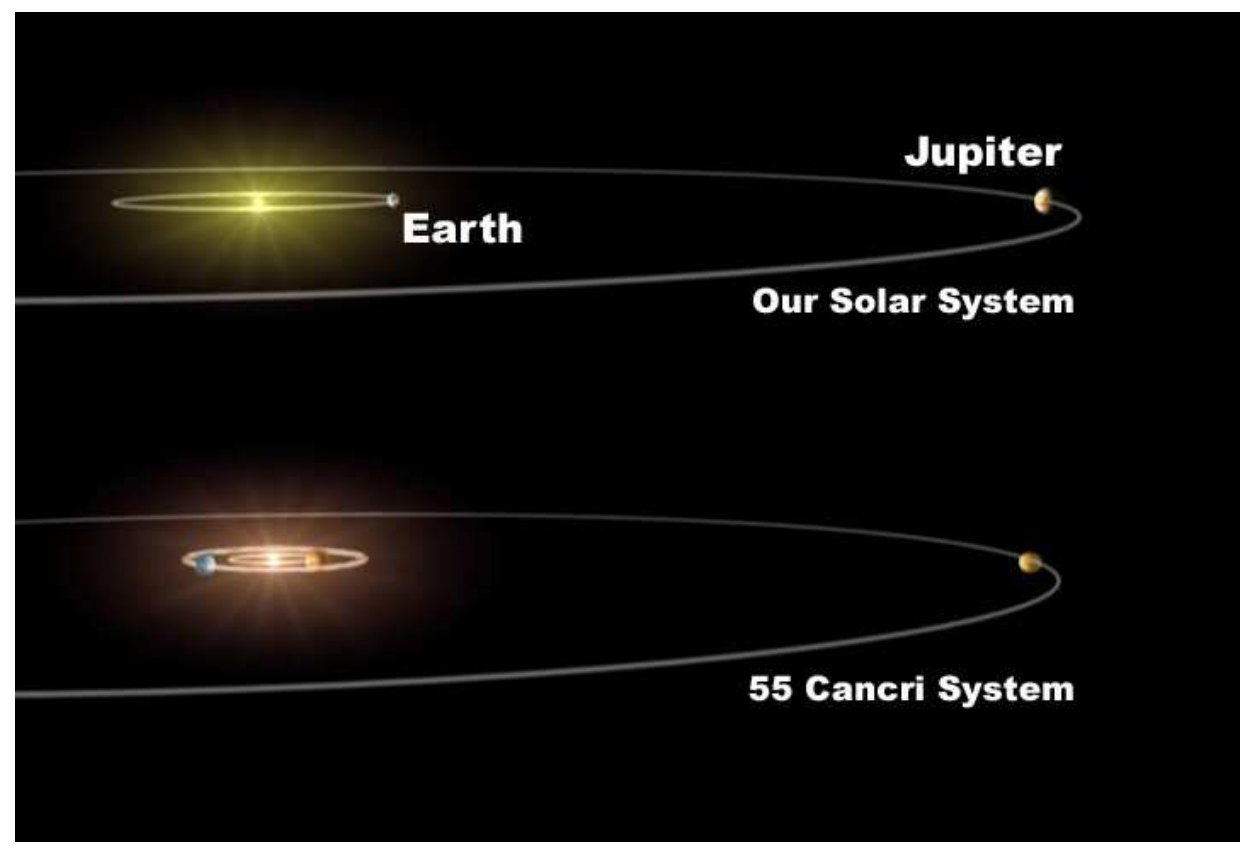

Fig. 7: Our solar system compared to 55 Cancri system 


\section{Results}

The first published discovery that was confirmed took place in 1988; a planet around the Gamma Cephei star was detected by Canadian astronomers Bruce Campbell, G.A. Walker and Stephenson Yang.

On February 26, 2014, NASA announced the confirmation of the discovery of 715 exoplanets with the Kepler Space Telescope. Four of the 715 planets are about 2.5 times larger than Earth and orbit in the habitable area of their star, defined as the distance from the star where the surface temperature is conducive to life in the aquatic environment. One of the lifethreatening expletives, called Kepler-296f, orbits around a star twice as small as the Sun. Kepler-296f is twice as big as Earth, but researchers do not know yet whether it is a gaseous planet, covered by a dense cloud of hydrogen and helium, or whether it is a planet rich in water surrounded by a deep ocean.

On Earth, ozone absorbs UV in the stratosphere, protecting our world from much of the harmful radiation of the Sun. For a stratospheric exoplanet, the absorbent is usually considered to be a molecule such as titanium oxide, a titanium dioxide near Earth as a paint pigment and a sunscreen.

Researchers analyzed the data collected for WASP18b (Fig. 8), located at 325 light-years from Earth, as part of a survey to find the planet with the stratosphere. The heavy planet, which has ten times the mass of the planet Jupiter, has been observed repeatedly, allowing astronomers to accumulate a relatively large volume of data. This study analyzed five eclipses from Hubble's archived data and two from Spitzer.

From the light emitted by the planet's atmosphere to infrared wavelengths, beyond the visible region, it is possible to identify spectral watermarks and other important molecules. The analysis highlighted the WASP-18b model, which does not resemble any exoplanet examined so far. To determine which of the molecules were most likely to match it, the team performed computerized modeling.

"The only consistent explanation of the data is overlapping carbon monoxide and very few water vapor in the WASP-18b atmosphere, in addition to the presence of a stratosphere," said Nikku Madhusudhan, co-author of Cambridge University in the UK. This rare combination of factors opens a new window in understanding physical and chemical processes in exoplanetary atmospheres.

The results show that WASP-18b has hotter carbon monoxide in the stratosphere and cooler carbon monoxide in the atmosphere below, called the troposphere. The team determined this by detecting two types of carbon monoxide signatures, an absorption signature at a wavelength of about 1.6 microns and an emission signature at about 4.5 microns. This is the first time scientists have detected both types of fingerprints for a single type of molecule in an exoplanet atmosphere.

In theory, another possibility of observation is carbon dioxide, which has a similar fingerprint. Researchers have decided this because, if there is enough oxygen to form carbon dioxide, the atmosphere should also have water vapor.

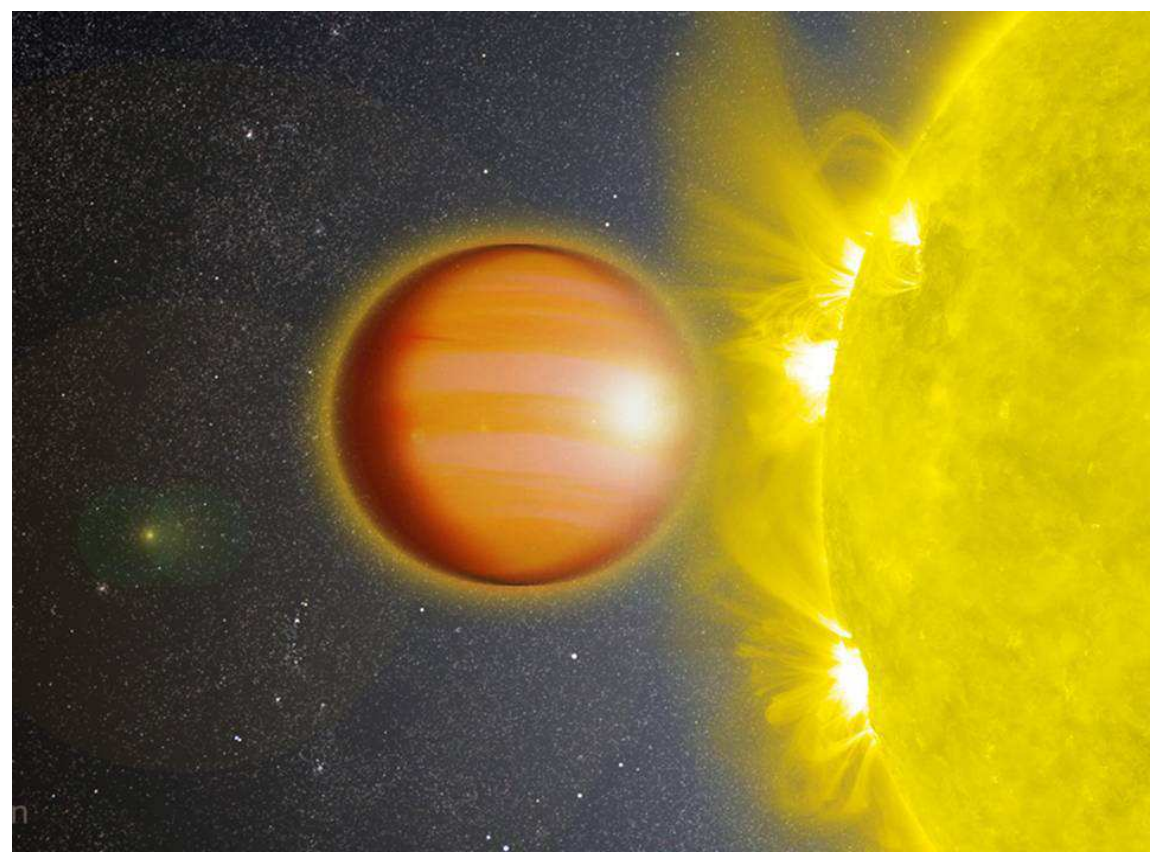

Fig. 8: WASP-18b, a "hot Jupiter" located 325 light-years from Earth, has a stratosphere that's loaded with carbon monoxide but has no signs of water 
To produce spectral impressions seen by the team, the top atmosphere of WASP-18b should be loaded with carbon monoxide. Compared to other planets, such as Jupiter, the atmosphere of this planet could contain 300 times more "metals" or heavier elements than hydrogen and helium. This extremely large metal would indicate that WASP-18b could have accumulated larger amounts of solid frost during its formation than Jupiter, suggesting that it could not have formed in another hot Jupiter.

WASP-18 is a 9-star magnitude located in the southern constellation of the Phoenix hemisphere. It has a mass of 1.25 masses of the sun.

In 2009, the SuperWASP project announced that an extraordinary planet Jupiter, WASP-18b, is in orbit very close to this star.

Observations of Chandra observer failed to find WASP-18 X-rays and it is believed that this is caused by the destruction of the magnetic field of the star by reducing the convection to the star's atmosphere. Tidal forces on the planet can also explain larger quantities of lithium measured in previous WASP-18 optical studies.

WASP-18b is an extrasolar planet that is notable for an orbital period of less than a day. It has a mass equal to 10 Jupiter masses, just below the boundary line between planets and brown dwarfs, about 13 Jupiter masses. Due to the tidal deceleration, it is expected to approach and eventually merge with the host star, WASP-18, in less than a million years. The planet has about 3.1 million kilometers of the star, which is about 325 light years away from Earth. It was discovered by a team led by Coel Hellier, professor of astrophysics at Keele University in England.

Keele researchers and the University of Maryland are trying to understand if the discovery of this planet, as small as its expected disappearance (with less than $0.1 \%$ of the remaining lifetime), has been forced or if the dissipation of the WASP-18 flow is much less effective than astrophysics. Observations made over the next decade should determine the rate at which they are in the WASP-18b orbit.

The closest example of a similar situation in the solar system is Phobos moon on Mars. Phobos orbits Mars at a distance of just $9,000 \mathrm{~km}, 40$ times closer to Earth than Earth and is expected to be destroyed in about eleven million years.

\section{Discussion}

In our Galaxy, there are billions of stars and it is estimated that over $15 \%$ of them have plants that surround them. There is also the planet that orbits around gray dwarf stars or plants that move freely through the galaxy.

The discovery of exoplanets is difficult because they are remote and lacking their own light. In June 2011, over 500 extrasolar planets have already been discovered. The mass of these planets is of the mass of the planet Jupiter. The vast majority of them have been detected through observations on radial speed and other indirect methods rather than using real images. To date, more than 2000 exoplanets have been discovered (2099 exoplanets in 1342 solar systems, of which 510 planetary systems with more than one planet on 1 April 2016).

Another method used to discover exoplanets is the technique of microgravity lenses, which is based on the deflection of light from a star when it is behind the gravity of the field of another star.

Several extragalactic exoplanets have been discovered.

Exoplanets are also important for the eventual existence of alien life because stars cannot shelter life, being too hot for it.

New bases built on Mars where people live are not only necessary but imperative to be built as quickly as possible.

Why is there an extension of the human species in space? Simple, because we will not all be here soon and after we're getting busy, we're gonna consume almost all of the planet's resources and then we'll have enormous social problems.

The man, as I have already said in other works, was not created here only to eat, drink and have fun. Our major humanitarian goal is to become multiple builders on various levels.

Over time, we have been able to make the blue planet special beauties built by humans, which even rivals those given by nature. But the big problem is that we will get more and more and resources will diminish. We have succeeded in starting to implement the green energy, especially the hydro, solar and wind, together with the initial nuclear fission energies soon and fusion and thus we will have energy at infinity, here on earth and wherever we go, energy to live, to move, to build and to other major needs.

In other words, if we cannot immediately reach other planets and colonize them, it is important to look for them, study them even remotely, to know what we have and in the future try to sort them to colonization actions could be launched in a timely manner, with great chances of success. Because these businesses will take us tens, hundreds and perhaps even thousands of years, it is imperative for humanity to immediately begin the colonization of what we have in our immediate vicinity.

\section{Conclusion}

Positioned approximately 70 light years from Earth a sun named by astronomer HD 97658, is nearly bright enough to be seen even with the naked eye.

The more interesting part of the problem lies in the fact that this sun, this star, also has an exoplanet HD $97658 \mathrm{~b}$, the size of which is approximately double compared to our planet Earth and having a smaller mass compared to our planet about eight times. HD $97658 \mathrm{~b}$ is 
basically a super-Earth, a great planet in cosmic space, for which there is no example in our solar system.

Even if its discovery was made long ago, its size and mass were recently determined by Diana Dragomir, a postdoctoral astronomer with the Las Cumbres Observatory Global Observatory (LCOGT) of UC Santa Barbara University. As part of his research, Dragomir carefully studied various transits of this exoplanet with the help of the cosmic telescope, able to determine Microvariability and Oscillations of Stars (MOST). That telescope was launched in 2003 in an orbit about 510 miles high. Dragomir has been able to analyze the data read by the telescope, using the code written by LCOGT postdoctoral colleague Jason Eastman. The results were recently published online in the Astrophysical Journal Letters.

It is considered a super planet, a super-Earth, an exoplanet having the mass and dimensions in the area of our solar system (between Earth and Neptune). It does not imply, as other obligatory researchers assert, the temperatures, the composition, the total similarity to the environment on Earth. These additional requirements are beyond the definition of a super-Earth and may represent additional desires. Superpowder refers to the mass of the planet and does not involve a temperature, composition or a similar environment on Earth.

The brightness of HD 97658 allows astronomers to study it closely, this star as well as its planet, in ways that are not possible for most exosystems (which have been discovered around the weaker stars).

HD 97658b was discovered relatively recently in 2011 by a team of specialized astronomers using the Keck Observatory and a technique called Doppler. Initially, only a lower limit could be established for the mass of the planet and nothing was known about its size.

Transits, such as those observed by Dragomir, can occur only when a planet's orbit is wearing it in front of the parent star, thus reducing the amount of light that we see from the star (so easy) when overlapping. The decrease in brightness occurs in each orbit if the orbit happens to be almost exactly aligned with our line of sight on Earth. For a planet that is not much larger than our Earth, around a star nearly as great as our Sun, the interruption in the light is very small and short but still detectable by the specialized telescope, MOST SPACE.

The first report on transit in the HD 97658 system in 2011 was just a false alarm, so the whole story of the new discovery risks to die from the beast and remain buried definitively. Dragomir knew that the ephemeris of the planet's orbit (a timing to predict when the planet could pass the star) was not accurate and had the power of persuasion for the MOST team not to stop research but to expand search parameters and then the last possible window of observation of this star last year when it all seemed just lost time and the abandonment of the study was already floating in the air, so the long awaited event occurred on its own, the data then showing tantalizing signs of a transit - monster, but unsafe though. So, resuming the abandonment study and only one year later, MOST revised HD 97658 and found clear evidence of the planet's transit, allowing Dragomir and the MOST team to evaluate them for the first time, including the size and mass of the planet.

After measuring the size and mass of the exoplanet, it was then possible to determine by its calculation its density, which in turn allows astronomers to continue to say something about its composition. The measurement of the properties of the super-earth, in particular, tells us whether they are mainly rocky giants, rich in water, mini-gas or something completely different. These are particularly complex problems that can be anticipated as soon as you know the first data about the mass, volume, density of a discovered exoplanet.

The average density of HD $97658 \mathrm{~b}$ is about four grams per cubic centimeter, about a third of the lead density, but denser than most known rocks. Astronomers see great value in this value - about $70 \%$ of Earth's average density - because the surface gravity of HD $97658 \mathrm{~b}$ could maintain a thick atmosphere. Although it is unlikely that alien life can breathe those gases, yet the planet allows them to exist and their possible later modification to obtain a friendly atmosphere. The planet orbits its sun every 9.5 days, at a distance ten times closer than we are from our Sun. If a planet is too close to its star, it is too hot; if it's too far away, it's too cold, but if it's in the area, it's "just right" for the ocean of liquid water, a prerequisite for the life here on Earth.

\section{Acknowledgement}

We acknowledge and thank $\mathrm{Mr}$ Taher M. AbuLebdeh, Associate Prof at North Carolina A and T State Univesity, United States and Mr Muftah H. El-Naas PhD MCIC FICCE QAFCO Chair Professor in Chemical Process Engineering Gas Processing Center College of Engineering Qatar University and Ms Shweta Agarwala, Senior Research Scientist at Singapore Center for 3D Printing Nanyang Technological University Singapore for their suggestions and comments.

\section{Funding Information}

Research contract: Contract number 36-5-4D/1986 from 24IV1985, beneficiary CNST RO (Romanian National Center for Science and Technology) Improving dynamic mechanisms internal combustion engines. All these matters are copyrighted. Copyrights: 548cgiywDssin, from: 22-04-2010, 08:48:48.

\section{Author's Contributions}

All the authors contributed equally to prepare, develop and carry out this manuscript. 


\section{Ethics}

This article is original and contains unpublished material. The corresponding author confirms that all of the other authors have read and approved the manuscript and no ethical issues involved.

\section{References}

Aversa, R., R.V.V. Petrescu, A. Apicella and F.I.T. Petrescu, 2017a. Nano-diamond hybrid materials for structural biomedical application. Am. J. Biochem. Biotechnol., 13: 34-41.

DOI: 10.3844/ajbbsp.2017.34.41

Aversa, R., R.V. Petrescu, B. Akash, R.B. Bucinell and J.M. Corchado et al., 2017b. Kinematics and forces to a new model forging manipulator. Am. J. Applied Sci., 14: 60-80. DOI: 10.3844/ajassp.2017.60.80

Aversa, R., R.V. Petrescu, A. Apicella, I.T.F. Petrescu and J.K. Calautit et al., 2017c. Something about the $\mathrm{V}$ engines design. Am. J. Applied Sci., 14: 34-52. DOI: 10.3844/ajassp.2017.34.52

Aversa, R., D. Parcesepe, R.V.V. Petrescu, F. Berto and G. Chen et al., 2017d. Process ability of bulk metallic glasses. Am. J. Applied Sci., 14: 294-301. DOI: 10.3844/ajassp.2017.294.301

Aversa, R., R.V.V. Petrescu, B. Akash, R.B. Bucinell and J.M. Corchado et al., 2017e. Something about the balancing of thermal motors. Am. J. Eng. Applied Sci., 10: 200-217.

DOI: 10.3844/ajeassp.2017.200.217

Aversa, R., R.V. Petrescu, A. Apicella and F.I.T. Petrescu, 2017f. Modern transportation and photovoltaic energy for urban ecotourism. Transylvanian Rev. Admin. Sci., 13: 5-20. DOI: 10.24193/tras.SI2017.1

Aversa, R., F.I.T. Petrescu, R.V. Petrescu and A. Apicella, 2016a. Biomimetic FEA bone modeling for customized hybrid biological prostheses development. Am. J. Applied Sci., 13: 1060-1067. DOI: 10.3844/ajassp.2016.1060.1067

Aversa, R., D. Parcesepe, R.V. Petrescu, G. Chen and F.I.T. Petrescu et al., 2016b. Glassy amorphous metal injection molded induced morphological defects. Am. J. Applied Sci., 13: 1476-1482. DOI: 10.3844 /ajassp.2016.1476.1482

Aversa, R., R.V. Petrescu, F.I.T. Petrescu and A. Apicella, 2016c. Smart-factory: Optimization and process control of composite centrifuged pipes. Am. J. Applied Sci., 13: 1330-1341.

DOI: 10.3844/ajassp.2016.1330.1341

Aversa, R., F. Tamburrino, R.V. Petrescu, F.I.T. Petrescu and M. Artur et al., $2016 \mathrm{~d}$. Biomechanically inspired shape memory effect machines driven by muscle like acting NiTi alloys. Am. J. Applied Sci., 13: 1264-1271.

DOI: 10.3844 /ajassp.2016.1264.1271
Aversa, R., E.M. Buzea, R.V. Petrescu, A. Apicella and M. Neacsa et al., 2016e. Present a mechatronic system having able to determine the concentration of carotenoids. Am. J. Eng. Applied Sci., 9: 1106-1111. DOI: 10.3844/ajeassp.2016.1106.1111

Aversa, R., R.V. Petrescu, R. Sorrentino, F.I.T. Petrescu and A. Apicella, 2016f. Hybrid ceramo-polymeric nanocomposite for biomimetic scaffolds design and preparation. Am. J. Eng. Applied Sci., 9: 1096-1105. DOI: 10.3844/ajeassp.2016.1096.1105

Aversa, R., V. Perrotta, R.V. Petrescu, C. Misiano and F.I.T. Petrescu et al., 2016g. From structural colors to super-hydrophobicity and achromatic transparent protective coatings: Ion plating plasma assisted $\mathrm{TiO}_{2}$ and $\mathrm{SiO}_{2}$ Nano-film deposition. Am. J. Eng. Applied Sci., 9: 1037-1045.

DOI: 10.3844 /ajeassp.2016.1037.1045

Aversa, R., R.V. Petrescu, F.I.T. Petrescu and A. Apicella, 2016h. Biomimetic and evolutionary design driven innovation in sustainable products development. Am. J. Eng. Applied Sci., 9: 1027-1036. DOI: 10.3844/ajeassp.2016.1027.1036

Aversa, R., R.V. Petrescu, A. Apicella and F.I.T. Petrescu, 2016i. Mitochondria are naturally micro robots-a review. Am. J. Eng. Applied Sci., 9: 991-1002. DOI: 10.3844/ajeassp.2016.991.1002

Aversa, R., R.V. Petrescu, A. Apicella and F.I.T. Petrescu, 2016j. We are addicted to vitamins $C$ and E-A review. Am. J. Eng. Applied Sci., 9: 1003-1018. DOI: 10.3844/ajeassp.2016.1003.1018

Aversa, R., R.V. Petrescu, A. Apicella and F.I.T. Petrescu, 2016k. Physiologic human fluids and swelling behavior of hydrophilic biocompatible hybrid ceramo-polymeric materials. Am. J. Eng. Applied Sci., 9: 962-972.

DOI: 10.3844 /ajeassp.2016.962.972

Aversa, R., R.V. Petrescu, A. Apicella and F.I.T. Petrescu, 20161. One can slow down the aging through antioxidants. Am. J. Eng. Applied Sci., 9: 1112-1126. DOI: 10.3844/ajeassp.2016.1112.1126

Aversa, R., R.V. Petrescu, A. Apicella and F.I.T. Petrescu, 2016m. About homeopathy or «Similia similibus curentur $\gg$. Am. J. Eng. Applied Sci., 9: 1164-1172. DOI: 10.3844/ajeassp.2016.1164.1172

Aversa, R., R.V. Petrescu, A. Apicella and F.I.T. Petrescu, 2016n. The basic elements of life's. Am. J. Eng. Applied Sci., 9: 1189-1197. DOI: 10.3844/ajeassp.2016.1189.1197

Aversa, R., F.I.T. Petrescu, R.V. Petrescu and A. Apicella, 2016o. Flexible stem trabecular prostheses. Am. J. Eng. Applied Sci., 9: 1213-1221. DOI: 10.3844/ajeassp.2016.1213.1221

Mirsayar, M.M., V.A. Joneidi, R.V.V. Petrescu, F.I.T. Petrescu and F. Berto, 2017. Extended MTSN criterion for fracture analysis of soda lime glass. Eng. Fracture Mechan., 178: 50-59. DOI: $10.1016 /$ j.engfracmech.2017.04.018 
Petrescu, F.I.T. and J.K. Calautit, 2016a. About nano fusion and dynamic fusion. Am. J. Applied Sci., 13: 261-266. DOI: 10.3844/ajassp.2016.261.266

Petrescu, F.I. and J.K. Calautit, 2016b. About the light dimensions. Am. J. Applied Sci., 13: 321-325. DOI: 10.3844/ajassp.2016.321.325

Petrescu, F.I. and R.V. Petrescu, 2011a. Memories about Flight. 1st Edn., CreateSpace, pp: 652.

Petrescu, F.I. and R.V. Petrescu, 2011b. Mechanical Systems, Serial and Parallel. 1st Edn., lulu.com Publisher, London, UK. ISBN-10: 1446600394 , pp: 124.

Petrescu, R.V. and F.I. Petrescu, 2013a. Lockheed Martin. 1st Edn., CreateSpace, pp: 114.

Petrescu, R.V. and F.I. Petrescu, 2013b. Northrop. 1st Edn., CreateSpace, pp: 96.

Petrescu, R.V. and F.I. Petrescu, 2013c. The Aviation History or New Aircraft I Color. 1st Edn., CreateSpace, pp: 292.

Petrescu, F.I. and R.V. Petrescu, 2013d. Cinematics of the 3R dyad. ENGEVISTA, 15: 118-124.

Petrescu, R.V. and F.I.T. Petrescu, 2012a. Northrop. 1st Edn., Books on Demand, ISBN-10: 3848209322, pp: 142.

Petrescu, F.I. and R.V. Petrescu, 2012b. New Aircraft II. 1 st Edn., Books on Demand, pp: 138.

Petrescu, F.I. and R.V. Petrescu, 2012c. MecatronicaSisteme Seriale Si Paralele. 1st Edn., Create Space Publisher, USA, ISBN-13: 978-1-4750-6613-5, pp: 128.

Petrescu, F.I. and R.V. Petrescu, 2012d. Kinematics of the planar quadrilateral mechanism. ENGEVISTA, 14: 345-348.

Petrescu, F.I. and R.V. Petrescu, 2016a. Parallel moving mechanical systems kinematics. ENGEVISTA, 18:455-491.

Petrescu, F.I. and R.V. Petrescu, 2016b. Direct and inverse kinematics to the anthropomorphic robots. ENGEVISTA, 18: 109-124.

Petrescu, F.I. and R.V. Petrescu, 2016c. Dynamic cinematic to a structure 2R. Revista Geintec-Gestao Inovacao E Tecnol., 6: 3143-3154.

Petrescu, R.V.V., R. Aversa, A. Apicella, F. Berto and S. Li et al., 2016a. Ecosphere protection through green energy. Am. J. Applied Sci., 13: 1027-1032.

DOI: 10.3844/ajassp.2016.1027.1032

Petrescu, F.I.T., A. Apicella, R.V.V. Petrescu, S.P. Kozaitis and R.B. Bucinell et al., 2016b. Environmental protection through nuclear energy. Am. J. Applied Sci., 13:941-946. DOI: 10.3844/ajassp.2016.941.946

Petrescu, R.V., R. Aversa, A. Apicella and F.I. Petrescu, 2016c. Future medicine services robotics. Am. J. Eng. Applied Sci., 9: 1062-1087.

DOI: 10.3844/ajeassp.2016.1062.1087

Petrescu, F.I.T., 2009. New aircraft. Proceedings of the 3rd International Conference on Computational Mechanics, Oct. 29-30, Brasov, Romania.
Petrescu, F.I.T., 2012a. Cold Nuclear Fusion. 1st Edn., Create Space, USA, ISBN-10: 1478234261, pp: 80.

Petrescu, F.I.T., 2012b. Particle annihilation - a source of renewable energy? Infinite Energy Magazine, LuLu Publishers, USA.

Petrescu, F.I.T., 2016 Valorificarea Traditiei Ingineresti Romanesti-I. 1st Edn., CreateSpace Independent Publishing Platform, ISBN-10: 1536889946, pp: 152.

Petrescu, R.V., R. Aversa, B. Akash, F. Berto and A. Apicella et al., 2017a. Forces of a 3R Robot. J. Mechatron. Robot., 1: 1-14.

DOI: $10.3844 /$ jmrsp.2017.1.14

Petrescu, R.V., R. Aversa, B. Akash, F. Berto and A. Apicella et al., 2017b. Direct geometry and cinematic to the MP-3R systems. J. Mechatron. Robot., 1: 15-23. DOI: 10.3844/jmrsp.2017.15.23

Petrescu, R.V., R. Aversa, B. Akash, F. Berto and A. Apicella et al., 2017c. Dynamic elements at MP3R. J. Mechatron. Robot., 1: 24-37. DOI: 10.3844 jmrsp.2017.24.37

Petrescu, R.V., R. Aversa, B. Akash, F. Berto, A. Apicella and F.I.T. Petrescu, 2017d. Geometry and direct kinematics to MP3R with $4 \times 4$ operators. J. Mechatron. Robot., 1: 38-46. DOI: $10.3844 /$ jmrsp.2017.38.46

Petrescu, R.V., R. Aversa, A. Apicella, M.M. Mirsayar and S. Kozaitis et al., 2017e. Current stage in the field of mechanisms with gears and rods. J. Mechatron. Robot., 1: 47-57. DOI: 10.3844 jmrsp.2017.47.57

Petrescu, R.V., R. Aversa, A. Apicella, M.M. Mirsayar and S. Kozaitis et al., 2017f. Geometry and inverse kinematic at the MP3R mobile systems. J. Mechatron. Robot., 1: 58-65. DOI: 10.3844 jmrsp.2017.58.65

Petrescu, R.V., R. Aversa, A. Apicella, M.M. Mirsayar and S. Kozaitis et al., 2017g. Synthesis of optimal trajectories with functions control at the level of the kinematic drive couplings. J. Mechatron. Robot., 1: 66-74. DOI: 10.3844 jmrsp.2017.66.74

Petrescu, R.V., R. Aversa, A. Apicella, M.M. Mirsayar and S. Kozaitis et al., 2017h. The inverse kinematics of the plane system 2-3 in a mechatronic MP2R system by a trigonometric method. J. Mechatron. Robot., 1: 75-87. DOI: 10.3844/jmrsp.2017.75.87

Petrescu, R.V., R. Aversa, A. Apicella, M.M. Mirsayar and S. Kozaitis et al., 2017i. Serial, anthropomorphic, spatial, mechatronic systems can be studied more simply in a plan. J. Mechatron. Robot., 1: 88-97. DOI: 10.3844/jmrsp.2017.88.97

Petrescu, R.V., R. Aversa, A. Apicella, M.M. Mirsayar and S. Kozaitis et al., 2017j. Analysis and synthesis of mechanisms with bars and gears used in robots and manipulators. J. Mechatron. Robot., 1: 98-108. DOI: $10.3844 / j m r s p .2017 .98 .108$ 
Petrescu, R.V., R. Aversa, A. Apicella, M.M. Mirsayar and S. Kozaitis et al., 2017k. Speeds and accelerations in direct kinematics to the MP3R systems. J. Mechatron. Robot., 1: 109-117.

DOI: $10.3844 / j m r s p .2017 .109 .117$

Petrescu, R.V., R. Aversa, A. Apicella, M.M. Mirsayar and S. Kozaitis et al., 20171. Geometry and determining the positions of a plan transporter manipulator. J. Mechatron. Robot., 1: 118-126. DOI: $10.3844 /$ jmrsp.2017.118.126

Petrescu, RV., R., Aversa, A., Apicella, M.M., Mirsayar and S. Kozaitis et al., 2018a. NASA Started a Propeller set on Board Voyager 1 After 37 Years of Break. Am. J. Eng. Applied Sci., 11: 66-77. DOI: 10.3844/ajeassp.2018.66.77

Petrescu, RV., R., Aversa, A., Apicella, M.M., Mirsayar and S., Kozaitis et al., 2018b. There is Life on Mars? Am. J. Eng. Applied Sci., 11: 78-91. DOI: 10.3844/ajeassp.2018.78.91

Petrescu, RV., R., Aversa, A., Apicella and FIT., Petrescu, 2018c. Friendly Environmental Transport. Am. J. Eng. Applied Sci., 11(1):154-165. DOI: 10.3844/ajeassp.2018.154.165

Petrescu, RV., R., Aversa, A., Apicella, et al., 2018d. Buses Running on Gas. Am. J. Eng. Applied Sci., 11: 186-201. DOI: 10.3844/ajeassp.2018.186.201

Petrescu, RV., R., Aversa, et al., 2018e. Some Aspects of the Structure of Planar Mechanisms. Am. J. Eng. Applied Sci., 11: 245-259.

DOI: 10.3844/ajeassp.2018.245.259

Petrescu, RV., R., Aversa, et al., 2018f. The Forces of a Simple Carrier Manipulator. Am. J. Eng. Applied Sci., 11: 260-272. DOI: 10.3844/ajeassp.2018.260.272

Petrescu, RV., R., Aversa, et al., 2018g. The Dynamics of the Otto Engine. Am. J. Eng. Applied Sci., 11: 273-287. DOI: 10.3844/ajeassp.2018.273.287

Petrescu, RV., R., Aversa, et al., 2018h. NASA Satellites Help us to Quickly Detect Forest Fires. Am. J. Eng. Applied Sci., 11: 288-296. DOI: 10.3844/ajeassp.2018.288.296

Petrescu, RV., R., Aversa, et al., 2018i. Kinematics of a Mechanism with a Triad. Am. J. Eng. Applied Sci., 11: 297-308. DOI: 10.3844/ajeassp.2018.297.308

Petrescu, RV., R., Aversa, et al., 2018j. Total Static Balancing and Kinetostatics of the 3R Base Cinematic Chain. J. Mechatron. Robot., 2: 1-13. DOI: $10.3844 /$ jmrsp.2018.1.13

Petrescu, RV., R., Aversa, et al., 2018k. Switching from Flat to Spatial Motion to 3R Mechatronic Systems. J. Mechatron. Robot., 2: 14-22. DOI: $10.3844 / j m r s p .2018 .14 .22$

Petrescu, RV., R., Aversa, et al., 20181. The Dynamics of the Planar Cinematic Balanced Chain at the Plan Module 3R. J. Mechatron. Robot., 2: 23-34.

DOI: $10.3844 / j m r s p .2018 .23 .34$
Petrescu, RV., R., Aversa, et al., 2018m. Dynamic Kinematics of the Plan Balanced Chain at the Planar Module 3R. J. Mechatron. Robot., 2: 35-44. DOI: $10.3844 /$ jmrsp.2018.35.44

Petrescu, RV., R., Aversa, et al., 2018n. Inverse Kinematics of a Stewart Platform. J. Mechatron. Robot., 2: 45-59. DOI: 10.3844/jmrsp.2018.45.59

Science Daily, 2013. Astronomer uncovers the hidden identity of an exoplanet. July 1, 2013. University of California - Santa Barbara. Source:

Webster, G., J. LaVista, L. Cantillo and D. Brown, 2018. Steep slopes on mars reveal structure of buried ice. Jet Propulsion Laboratory, Pasadena, California Institute of Technology.

Zubritsky, E., 2017. Exoplanet has smothering stratosphere without water. NASA's Jet Propulsion Laboratory, Pasadena, California Institute of Technology.

\section{Source of Figures}

Fig. 1:

https://www.sciencedaily.com/images/2013/07/1307011 63941_1_900x600.jpg

Fig. 2:

https://upload.wikimedia.org/wikipedia/ro/8/8c/NASA Alien_World1.jpg

Fig. 3:

https://upload.wikimedia.org/wikipedia/commons/thumb /0/05/Planet_Discovery_Neighbourhood_in_Milky_Way Galaxy.jpeg/1024px-

Planet_Discovery_Neighbourhood_in_Milky_Way_Gala xy.jpeg

Fig. 4:

https://upload.wikimedia.org/wikipedia/commons/thumb/a/ a3/Fomalhaut_with_Disk_Ring_and_extrasolar_planet_b.jp g/1024px-

Fomalhaut_with_Disk_Ring_and_extrasolar_planet_b.jpg

Fig. 5:

https://upload.wikimedia.org/wikipedia/commons/3/39/ GJ_758_System_-_Labeled.jpg

Fig. 6:

https://upload.wikimedia.org/wikipedia/commons/1/11/T he_Star_AB_Pictoris_and_its_Companion_-_Phot-14d05-normal.jpg

Fig. 7:

https://upload.wikimedia.org/wikipedia/commons/5/59/E xtrasolar_planet_NASA2.jpg

Fig. 8:

https://www.jpl.nasa.gov/news/news.php?feature $=7012$ 